\title{
GENERALIZATION THEOREM ON CONVERGENCE AND INTEGRABILITY FOR SINE SERIES
}

\author{
ŽIVORAD TOMOVSKI
}

Abstract. In this paper a generalization of the Zahid's theorem for convergence and integrability for sine series (see [9]) is made by considering the class $S_{p}(\delta), p>1$ instead of $S(\delta)$.

Mathematics subject classification (1991): 26D15, 42A20.

Key words and phrases: $\delta$-quasi-monotone sequence, trigonometric series, Fourier series, Dirichlet kernel, Abel's transformation, Hölder inequality, Hausdorff-Young inequality.

\section{REFERENCES}

[1] BoAs, R. P., Quasi-positive sequence and trigonometric series, Proc. Lond. Math. Soc. 14 A (1965), 38-48.

[2] Duren, P. P. L., Theory of $H^{p}$ spaces, Academic Press, New York, 1970.

[3] Fomin, G. A., A class of trigonometric series, Math. Notes 23 (1978), 117-124, (Russian).

[4] Fomin, G. A., On linear method for summing Fourier series, Mat. Sb. 66 (1964), 144-152, (Russian).

[5] GARRETT, J.W. AND ČASLAV V. STANOJEVIĆ, On $L^{1}$ convergence of Fourier series with quasi-monotone coefficients, Proc. Amer. Math. Soc. 72 (1978), 535-538.

[6] Garrett, J. W. AND ČASlaV V. Stanojević, Necessary and sufficient condition for $L^{1}$ convergence of trigonometric series, Proc. Amer. Math. Soc. 60 (1976), 68-71.

[7] TelyakovskiI, S. A., Concerning a sufficient condition of Sidon for the integrability of trigonometric series, Math. Notes 14 (1973), 742-748, (Russian).

[8] Tomovski Ž., An application of the Hausdorff-Young inequality, Mathematical Inequalities \& Applications 1(4) (1998), 527-532.

[9] ZAHID S. A. Z., Integrability of trigonometric series, Tamkang, J. Math. 21 (1990), 295-301. 